\title{
Análise da distribuição espacial da cobertura vegetal no município de Santa Barbara/PA
}

As questões voltadas ao entendimento das alterações ambientais têm despertado forte preocupação da sociedade diante das grandes catástrofes naturais e 0 empobrecimento dos recursos naturais. Uma ferramenta de relevante importância na detecção, descrição, quantificação e monitoramento de alterações ambientais é o Sistema de Informação Geográfica (SIG), o qual combinado com dados de Sensoriamento Remoto (SR), se torna uma ferramenta de manejo de grande valia para os ecossistemas em geral. A vegetação é um importante indicador geoambiental, pois sofre influência dos fatores climáticos, edafológicos e bióticos. $O$ Índice de Vegetação da Diferença Normalizada tem sido utilizado para estudos referentes à dinâmica da cobertura vegetal e suas características em relação ao comportamento espectral de alvos. Objetivo do presente trabalho foi investigar o comportamento da vegetação na localidade do município de Santa Barbara/PA para interpretação da organização do espaço geográfico e modificações. Foi utilizado imagem do satélite Landsat 8 ETM+ disponibilizada pelo Science for Changing world - USGS data de 06 de julho de 2017 o Datum utilizado foi WGS 1984 UTM Zona_22 S, os procedimentos foram realizados em ambiente SIG, utilizando o software ArcGis 10.5. Esse método consiste de a vegetação fotossinteticamente ativa estará se utilizando da luz no comprimento de onda compreendido pelo vermelho, mas como não faz uso do infravermelho próximo, estará refletindo-a. Do uso destes parâmetros de reflectância obter-se-á um índice, o NDVI. Os resultados demostram variedade de cobertura vegetal que sofre variação ao logo das rodovias e dinâmica da pratica de agricultura na região.

Palavras-chave: Território; Análise ambiental; SIG.

\section{Analysis of spatial distribution of vegetation coverage in the municipality of Santa Barbara/PA}

\begin{abstract}
Issues related to the understanding of environmental changes have aroused a strong concern of society in the face of major natural disasters and the impoverishment of natural resources. A tool of relevant importance in the detection, description, quantification and monitoring of environmental changes is the Geographic Information System (GIS), which combined with Remote Sensing (SR) data, becomes a valuable management tool for ecosystems. Generally. Vegetation is an important geo-environmental indicator, as it is influenced by climatic, edaphologic and biotic factors. The Normalized Difference Vegetation Index has been used for studies regarding the dynamics of vegetation cover and its characteristics in relation to the spectral behavior of targets. Objective of the present work was to investigate the behavior of vegetation in the city of Santa Barbara/PA to interpret the organization of the geographical space and changes. An image of the Landsat 8 ETM + satellite made available by Science for Changing world - USGS, dated July 6, 2017, was used. The Datum used was WGS 1984_UTM Zona_22 S, the procedures were performed in a GIS environment, using the ArcGis 10.5 software. This method consists of the photosynthetically active vegetation using light at the wavelength comprised by red, but since it does not use near infrared, it will be reflecting it. Using these reflectance parameters, an index, the NDVI, will be obtained. The results show a variety of vegetation cover that varies along the highways and dynamics of agricultural practice in the region.
\end{abstract}

Keywords: Territory; Environmental analysis; SIG.

Erick dos Santos Ribeiro (iD)

Universidade Federal Rural da Amazônia, Brasil http://lattes.cnpq.br/9915795223042598 http://orcid.org/0000-0002-0477-1588 ericksantos39@hotmail.com

\section{Sayure Mariana Raad}

Universidade Federal Rural da Amazônia, Brasil http://lattes.cnpq.br/8281827404307486 http://orcid.org/0000-0002-4127-7351

raadsayure@gmail.com

Raqueli Solange Corrêa Nascimento (iD Universidade Federal Rural da Amazônia, Brasil http://lattes.cnpq.br/8366335278946569 http://orcid.org/0000-0003-3177-1337 raquelisolange@hotmai.com

\author{
Nestor Silva dos Reis (D) \\ Universidade Federal Rural da Amazônia, Brasil \\ http://lattes.cnpq.br/8259661679255773 \\ http://orcid.org/0000-0001-8971-8198 \\ nestor.silva21@gmail.com \\ Barbara Luzia Santos de Oliveira Faro \\ Universidade Federal Rural da Amazônia, Brasil \\ http://lattes.cnpq.br/4101003024892787 \\ http://orcid.org/0000-0002-8764-7274 \\ barbarafaro7@gmail.com \\ Francimary da Silva Carneiro (iD) \\ Universidade Federal Rural da Amazônia, Brasil \\ http://lattes.cnpq.br/8657235544233319 \\ http://orcid.org/0000-0002-1693-8779 \\ francimarycarneiro@gmail.com
}

Jéssica Costa dos Santos (iD

Universidade Federal Rural da Amazônia, Brasil http://lattes.cnpq.br/8061391874732225 http://orcid.org/0000-0002-4424-1821 jessicasantos.ufra@gmail.com

\section{Referencing this:}

RIBEIRO, E. S.; RAAD, S. M.; NASCIMENTO, R. S. C.; REIS, N. S.; FARO, B. L. S. O.; CARNEIRO, F. S.; SANTOS, J. C.. Análise da distribuição espacial da cobertura vegetal no município de Santa Barbara/PA. Natural Resources, v.10, n.3, p.8-14, 2020. DOI:

DOI: 10.6008/CBPC2237-9290.2020.003.0002 http://doi.org/10.6008/CBPC2237-9290.2020.003.0002 


\section{INTRODUÇÃO}

Uma ferramenta de relevante importância na detecção, descrição, quantificação e monitoramento de alterações ambientais é o Sistema de Informação Geográfica (SIG), o qual combinado com dados de Sensoriamento Remoto (SR), se torna uma ferramenta de manejo de grande valia para os ecossistemas em geral (KRUG et al., 2007).

As questões voltadas ao entendimento do uso e cobertura do solo têm despertado forte interesse dentro e fora do meio científico. Isso tem ocorrido motivado pelo acelerado processo de mudança dos aspectos da superfície, que, por sua vez, associam-se aos diversos impactos ambientais e socioeconômicos oriundos, especialmente, dos processos antrópicos. A vegetação é um importante indicador geoambiental, pois sofre influência dos fatores climáticos, edafológicos e bióticos. Exerce importante papel na estabilização dos geoambientes, visto que protegem o solo dos processos erosivos, facilita a distribuição, infiltração e acumulo das águas pluviais e influência nas condições climáticas do ambiente (ALMEIDA et al., 2012).

Nesse contexto, o Índice de Vegetação da Diferença Normalizada (NDVI - Normalized Difference Vegetation Index) tem sido utilizado para estudos referentes à dinâmica da cobertura vegetal e suas características em relação ao comportamento espectral de alvos. Pois tendo em vista que a degradação ambiental é um dos problemas mais preocupantes atualmente, o estudo da dinâmica da cobertura vegetal é de extrema importância, para a conscientização e responsabilidade perante as consequências ambientais e sociais que poderá causar (SANTOS et al., 2015).

A modelagem dos índices de vegetação baseia-se no comportamento oposto da refletância da vegetação na região do visível, ou seja, quanto maior a densidade vegetal, menor é a refletância em função da absorção da radiação pelos pigmentos fotossintetizantes e quanto maior a densidade vegetal, maior a refletância devido ao espalhamento nas diferentes camadas das folhas (BORATTO et al., 2013). Objetivo do presente trabalho foi analisar através do NDVI o comportamento da vegetação na localidade do município de Santa Barbara/PA para interpretação da organização do espaço geográfico e modificações na cobertura vegetal diante do desenvolvimento da agricultura e crescimento urbano.

\section{MATERIAIS E MÉTODOS}

Para análise de geoprocessamento foi utilizado imagem do satélite Landsat 8 ETM+ disponibilizada pelo Science for Changing world - USGS data de 06 de julho de 2018 o Datum utilizado foi WGS_1984_UTM_Zona_22 S, os procedimentos foram realizados em ambiente SIG, utilizando o software ArcGis 10.5. O município em estudo localiza-se a uma latitude 0113'25" sul e a uma longitude 4817'40" oeste, Santa Bárbara do Pará (Figura 1) que foi criado por meio da Lei no 5.693, de 13 de dezembro de 1991, sancionada pelo governador Jáder Barbalho. Foi desmembrado do município de Benevides, com sede na localidade de vila de Santa Bárbara, que passou à categoria de Cidade, com a denominação de Santa Bárbara do Pará. A região apresenta grande pratica no ramo da agricultura e pecuária. Além de grande influência da bacia hidrográfica do Rio Araci. 


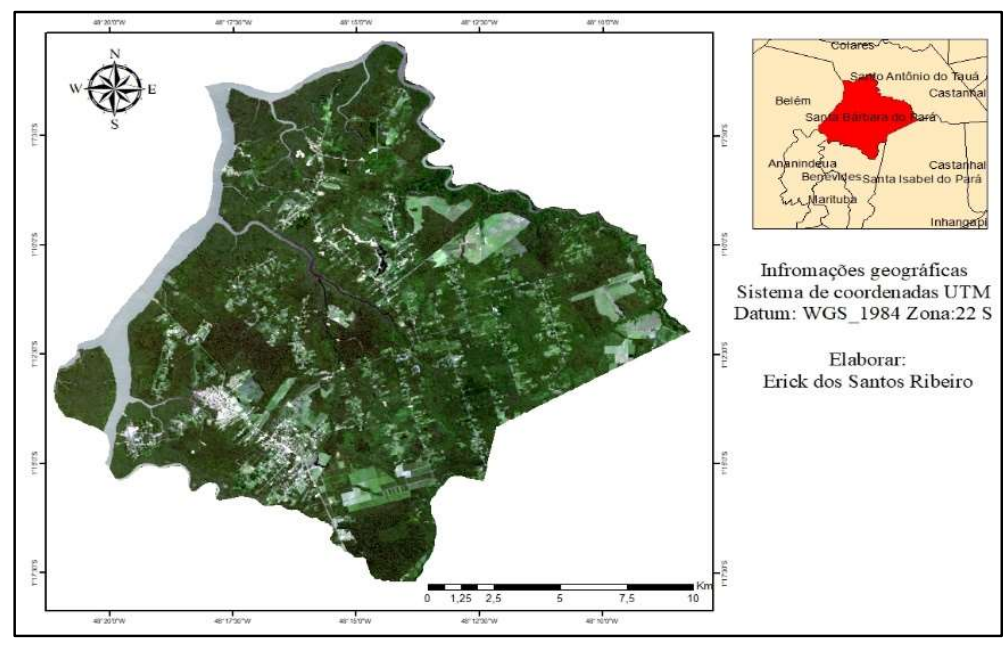

Figura 1: Mapa de localização do município de Santa Barbara do Pará.

Para realização do NDVI, foi aplicado o algoritmo (ROUSE JUNIOR et al., 1973) que consiste na diferença da refletância no infravermelho próximo e a refletância no vermelho dividido pela soma dessas duas bandas como mostra a seguinte equação:

$$
\mathrm{NDVI}=((R i v p-R v) /(R i v p+R v))
$$

Onde: $\mathrm{R}=$ reflectância; ivp = espectro eletromagnético infravermelho; $v=$ espectro eletromagnético vermelho.

$\mathrm{Na}$ etapa de analise para identificação das radiações espectrais que representam a energia solar refletida por cada pixel, por unidade de área, de tempo, do ângulo sólido e do comprimento de onda, medida nos sensores a bordo do satélite, que no caso do Landsat 8 TM correspondem as medidas realizadas nos canais 1, 2, 3, 4, 5 e 6 (Tabela 1 ).

Tabela 1: Características espectrais dos instrumentos imageadores OLI e TIRS. ${ }^{1}$

\begin{tabular}{lll}
\hline Landsat-8 Bands & Comprimento de onda (micrômetros) & Resolução (metros) \\
\hline Band 1 - Coastal aerosol & $0.43-0.45$ & 30 \\
Band 2 - Blue & $0.45-0.51$ & 30 \\
Band 3 - Green & $0.53-0.59$ & 30 \\
Band 4 - Red & $0.64-0.67$ & 30 \\
Band 5 - Near Infrared (NIR) & $0.85-0.88$ & 30 \\
Band 6 - SWIR 1 & $1.57-1.65$ & 30 \\
\hline
\end{tabular}

Usando a ferramenta - Imag Analysis no Menu Windows, foi selecionada as bandas e clicado na opção NDVI para formação do mapa, surgido um raster com Tons de cinza que foi ajustado no guia symbology para cores das 6 classes escolhidas (Tabela 2). Para melhor observação das características peculiares do município referente a cobertura vegetal da área de estudo.

Tabela 2: Intervalos das respectivas classes e alvos de superfície do NDVI.

\begin{tabular}{lll|}
\hline Intervalos de NDVI & Classes & Alvos de superfície \\
\hline$-0,24--0,02$ & Classes 1 & Corpos d'água \\
$-0,02-0,21$ & Classes 2 & Áreas sem Vegetação \\
$0,21-0,35$ & Classes 3 & Vegetação decídua menos densa \\
$0,35-0,43$ & Classes 4 & Vegetação decídua mais densa \\
$0,43-0,47$ & Classes 5 & Vegetação Semidecídua \\
$0,47-0,61$ & Classes 6 & Vegetação Perenifólia \\
\hline
\end{tabular}

${ }^{1}$ http://www.processamentodigital.com.br 
Esse método consiste de a vegetação fotossinteticamente ativa estará se utilizando da luz no comprimento de onda compreendido pelo vermelho, mas como não faz uso do infravermelho próximo, estará refletindo-a. Do uso destes parâmetros de reflectância obter-se-á um índice, o NDVI. Longo após foi feito sobreposição do arquivo shapefile do município para realizar o corte da área de interesse com a ferramenta clip no software Arcgis 10.5 o corte da imagem.tiff para destaque do local da pesquisa (Figura 2).

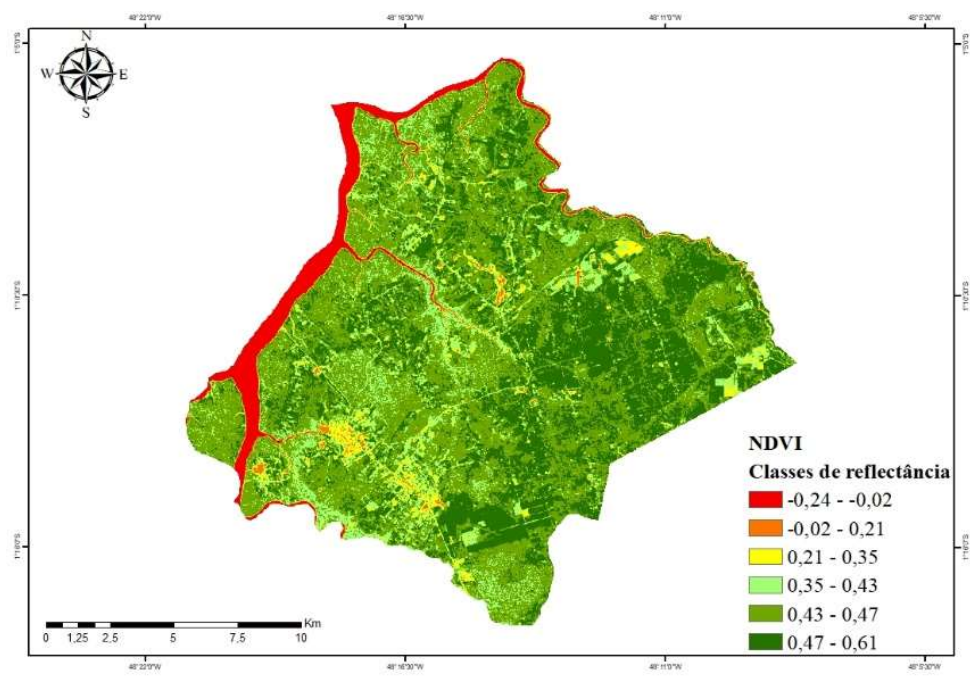

Figura 2: Mapa o Índice de Vegetação da Diferença Normalizada do município de Santa Barbara do Pará.

O produto obtido foi dividido em 6 intervalos de reflectância, pois essa quantidade de intervalos exibiu o melhor agrupamento das classes de acordo com a resposta espectral dos alvos, variado de $-0,24$ a 0,61 por pixel, de modo que quanto mais próximo de +1 , maior a densidade da vegetação sendo que a medida em que esse valor diminui, a vegetação vai ficando mais rala próxima de -1 , maior indício de alteração na vegetação.

Com relação a classe de Áreas sem Vegetação (uso antrópico) e sua definição, foram considerados os setores onde havia predominância de alvos com comportamentos espectrais característicos de áreas urbanas, sítios, áreas de urbanização incipiente, comunidades rurais, vias de acesso, agricultura família bem como outras áreas onde houve supressão da cobertura vegetal e foram modificadas pelas ações humanas. Para tal constatação foi realizado um trabalho campo que tiveram início no mês de agosto de 2016, com o intuito de observar a expressão da cobertura vegetação e a ocupação feita do município.

\section{RESULTADOS E DISCUSSÃO}

Através do produto gerado pelo NDVI, foi possível observar a diferença na distribuição na cobertura vegetal, na figura 2 os elementos visuais mais representativos são os de valores positivos, o que sugere a presença de cobertura vegetal, os valores de NDVI foram agrupados em seis classes e seus respectivos alvos de superfície identificados em campo.

Os valores negativos representados na classe1 são corpos d'água que devido a sua característica físico química, com valores de $(-0,24--0,02)$, a maior parte do fluxo incidente sobre a água pura não é refletida, como ocorre no solo e na vegetação, mas sim absorvido ou transmitida. Nos comprimentos de onda 
do visível, pouca luz é absorvida, uma pequena quantidade é refletida e a maior parte é transmitida (MANTOVANI, 1993). A classe 2 assim como a classe 1, é indicativa de superfícies sem vegetação. No entanto corresponde a locais com solos descobertos, rochas, áreas urbanizadas e outras áreas sem vegetação, com índices entre -0,02 -0,21, interpretando pela cor laranja com pouca predominância na localidade. Durante o trabalho de campo foi observado parte dessa alteração se relaciona a ação antrópica da retirada de solo para formação de piçarra e produção artesanal em pequena escala de carvão na região (Figura 3).

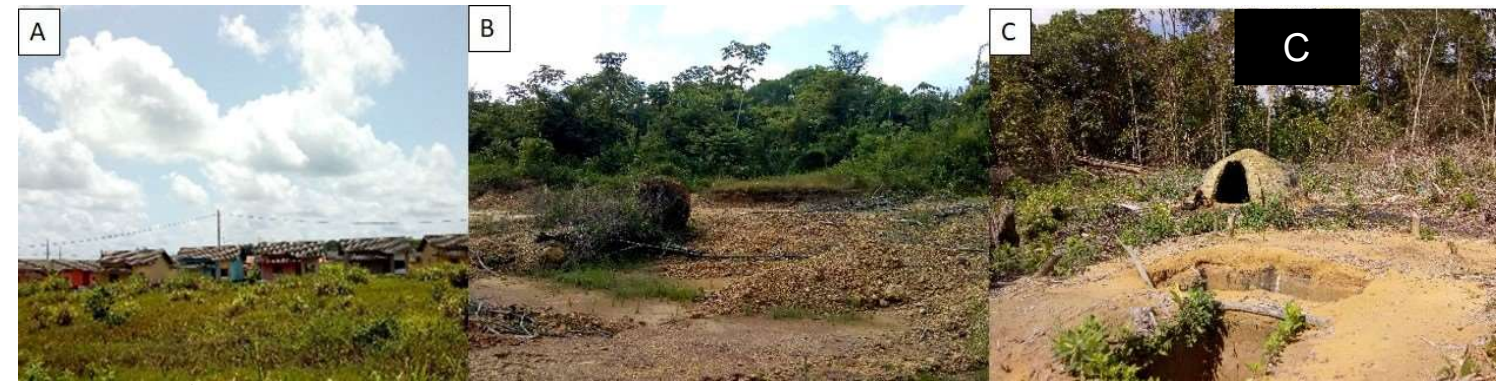

Figura 3: A) Áreas urbanas. B) Retirada de solo para obtenção de piçarra. C) Produção artesanal de carvão.

Ao que concerne às classes vegetadas, a classe 3 estão agrupados os intervalos de valores positivos relacionados ao NDVI, variou de $(0,21-0,35)$. Demostrado vegetação de baixa atividade fotossintética, com alvos de superfície onde ocorrem a mistura espectral das áreas sem vegetação com áreas de cobertura vegetal menos densa. Relacionada com plantas de uso agronômico (Mandioca, dendê, açaí, cacau e outros), que devido aos diferentes espaçamentos feito durante sua implantação demostra a redução não ação fotossintética dos alvos. Na localidade se observou muitas produções voltadas para agricultura família de subsistência, assim como desenvolvimento de Sistema agroflorestais e indústria de exploração de dendê (Figura 4).

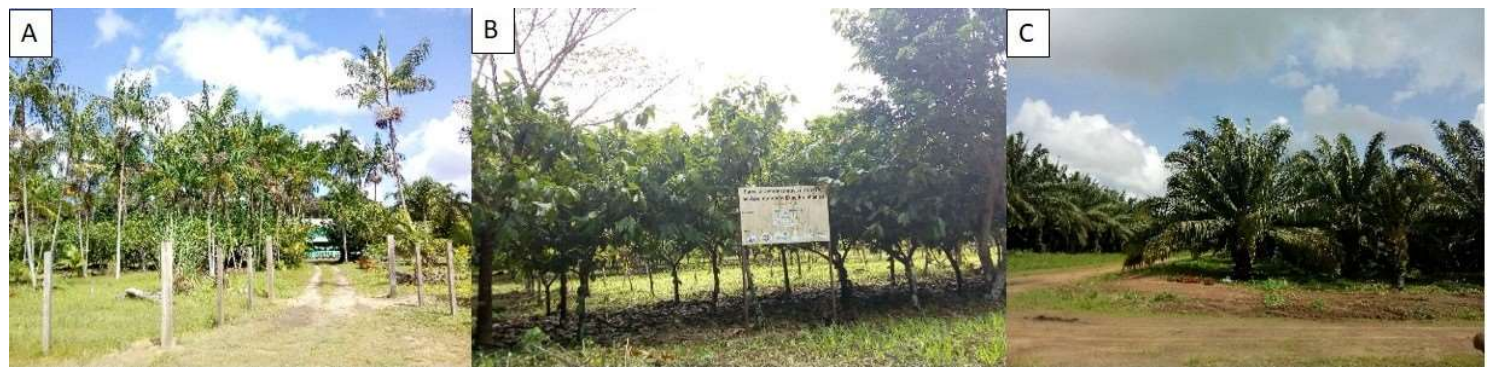

Figura 4: A) Agricultura família. B) Implantação de SAFs no assentamento expedido ribeiro pela Tokyo university. C) Plantação de dendê da empresa DENPASA - PA.

A temática da classe 4 medidas valores de reflectância agrupados entre $(0,35-0,43)$ demostra vegetação de crescimento espontâneo, com grande distribuição geoespacial dessa classe ocorre de forma dispersa ou agrupada, principalmente nas áreas de leitos de rios e igarapés, refletido as plantas de várzea alta e baixa que acompanha as margens dos rios, onde partículas maiores de sedimentos são depositadas. Apesar de possuir certa resiliência, as várzeas são ambientes frágeis. Com a atual forma de ocupação e uso pode levar à degradação progressiva dessas áreas. No território a grande pratica de captura de peixes e camarão pela população ribeirinha. Surgimento de balneários nos leitos rios e igarapés para o lazer e comercio (Figura 5). 


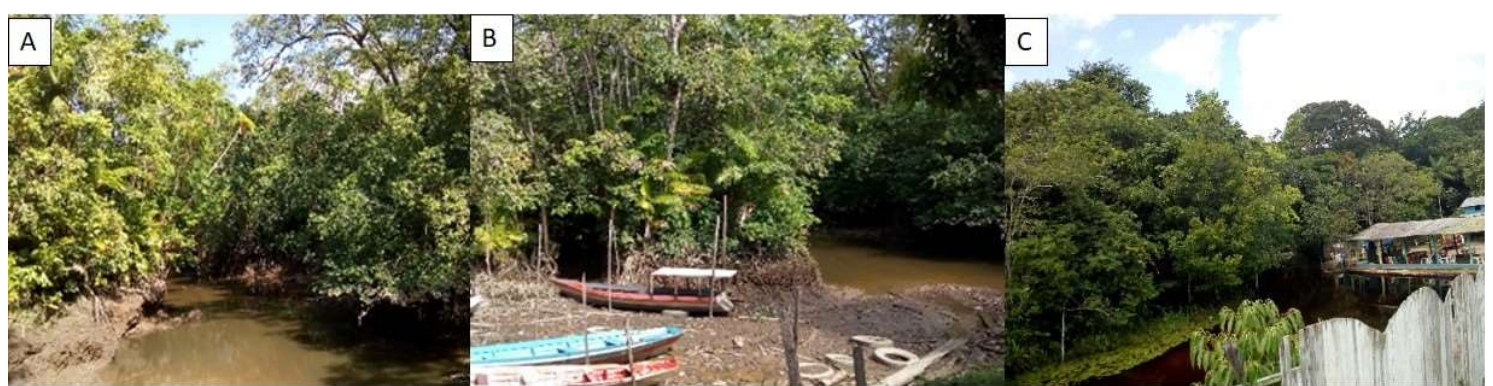

Figura 5: A) Floresta de várzea. B) Ocupação de área para pesca de peixe e camarão. C) surgimento de balneários na margem de rios e igarapés.

No que se refere a classe 5 retratar vegetação um nível de cobertura vegetal superior a classe 4, porém ainda incipiente no que diz respeito a atividade fotossintética e presença de clorofila, de acordo com os parâmetros deste índice. Que pode estar associado a organismo de pequeno porte como arbustos e forrageiras utilizadas na pecuária. Estão em arranjos em grande parte espacialmente por todas as feições do relevo, principalmente nas áreas de alta alteração pela agricultura, pecuária e urbanização (Figura 6).

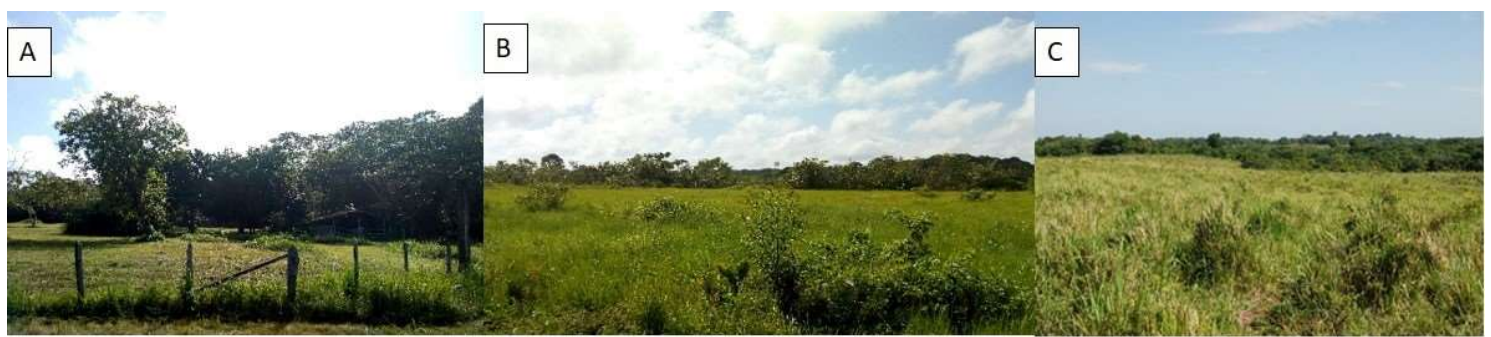

Figura 6. A) vegetação rala. B) Distribuição de plantas arbustivas. C) Forrageira utilizada na pecuária.

Na última classe 6 são demostrados grande expressão de acordo com o mapa de NDVI valor, máximo de 0,60 demostrado áreas para a vegetação verde de maior atividade fotossintética e densa, como sugere o índice uma vegetação perenifólia. Com grande dominância no espaço geográfico da localidade cujas folhas são mantidas durante todo o ano, sendo essencial seu zoneamento e preservação. Foi observando que maiores partes do espaço geográfico apresentam projetos de reflorestamentos e agrossistemas voltados para a preservação da água e excetivo conservação da floresta (Figura 7).

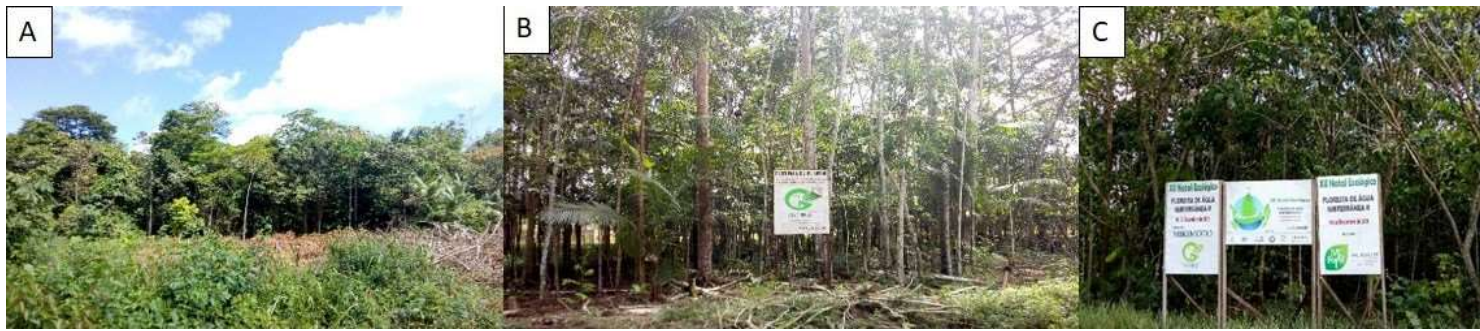

Figura 7: A) Vegetação Perenifólia. B) Pratica de reflorestamento em Assentamento Expedito Ribeiro. C) Conservação da água através da floresta de água subterrânea.

\section{CONCLUSÕES}

Os dados mostram alteração da vegetação nos cursos das rodovias e nos assentamentos na superfície do terreno. Além das ações de indústrias e comunidades tradicionais que pratica diversas formas de produção agrícola que favorece diversificação na cobertura verde da localidade. 


\section{REFERÊNCIAS}

ALMEIDA, N. V.; CUNHA, S. B.; NASCIMENTO, F. R.. A cobertura vegetal e sua importância na análise morfodinâmica da bacia hidrográfica do Rio Taperoá, nordeste do Brasil/Paraíba. Revista Geonorte, v.3, n.4, p.365-378, 2012.

BORATTO, I. M. P; GOMIDE, R. L.. Aplicação dos índices de vegetação NDVI, SAVI e IAF na caracterização da cobertura vegetativa da região Norte de Minas Gerais. In: SIMPÓSIO BRASILEIRO DE SENSORIAMENTO REMOTO - SBSR, 16. Anais. Foz do Iguaçu: INPE, 2013.

KRUG, L. A.; LEÃO, C.; AMARAL, S.. Dinâmica espaçotemporal de manguezais no Complexo Estuarino de Paranaguá e relação entre decréscimo de áreas de manguezal e dados socioeconômicos da região urbana do município de Paranaguá - Paraná. In: SIMPÓSIO BRASILEIRO DE SENSORIAMENTO REMOTO, 13. Anais. Florianópolis: INPE, 2007. p.2753-2760.
MANTOVANI, J. E.. Comportamento espectral da água: faixas espectrais de maior sensibilidade ao fitoplâncton na presença de matéria orgânica dissolvida e de matéria inorgânica particulada. São Jose dos Campos: INPE, 1993. p.1-119.

ROUSE JUNIOR, J. W.; HAAS, R. H.; SCHELL, J. A.; DEERING, D. W.. Monitoring vegetation systems in the great plains with ERTS. In: EARTH RESOURCES TECHNOLOGY SATELLITE-1 SYMPOSIUM, 3. Anais. Washington, 1973. p.309-317.

SANTOS, F. A.; OLIVEIRA, W. A. S.. Aplicação do índice de vegetação por diferença normalizada (NDVI) para avaliação da cobertura vegetal do entorno do Açude Caldeirão, em Piripiri (PI), BRASIL. Revista Equador, v.4, n.2, p.114$127,2015$.

A CBPC - Companhia Brasileira de Produção Científica (CNPJ: 11.221.422/0001-03) detém os direitos materiais desta publicação. Os direitos referem-se à publicação do trabalho em qualquer parte do mundo, incluindo os direitos às renovações, expansões e disseminações da contribuição, bem como outros direitos subsidiários. Todos os trabalhos publicados eletronicamente poderão posteriormente ser publicados em coletâneas impressas sob coordenação da Sustenere Publishing, da Companhia Brasileira de Produção Científica e seus parceiros autorizados. Os (as) autores (as) preservam os direitos autorais, mas não têm permissão para a publicação da contribuição em outro meio, impresso ou digital, em português ou em tradução. 